Journal of Service Research, N²5/1 (2022), PP 66-85 (POST PRINT)

DOI: $10.1177 / 10946705211044838$

\title{
Vital service captivity: coping strategies and identity negotiation
}

\author{
Samuel GUILLEMOT, Univ Brest, LEGO, Quimper, France \\ Margot DYEN, Univ Savoie-Mont-Blanc, IREGE, Annecy, France
}

Annick TAMARO, Univ Brest, LEGO, Quimper, France

\begin{abstract}
Nursing homes are the quintessential example of vital service captivity. Consumers need vital services when they can no longer fulfil their basic needs on their own and their only choice is to delegate them to the market (e.g. care services for long-term and chronic illnesses, eating assistance at mealtimes). The service is referred to as "captive" because older people are generally unwilling to use it, and when they have to, their options are limited. For elderly consumers, there is "no exit possible", and as such they must integrate the service into their sense of self. The paper aims to (1) identify strategies for coping with vital service captivity and (2) present the identity negotiation mechanisms that lead people to choose one strategy over another. The study was conducted over a six-month period in three nursing homes. Data collection includes semi-structured interviews, focus groups, participant observations, and micro-interviews with consumers - elderly residents and their families - and nursing home staff. Its main contribution is to highlight that coping with vital service captivity is a differential process. Consumers implement multiple coping strategies simultaneously and these strategies are linked to three areas: routinization, socialization, and assimilation of a new social status. Moreover, implementing coping strategies means striking a balance between "disengagement" and "engagement" that not only takes into account former life trajectory, future prospects and social comparisons, but also any changes in physical or cognitive skills and family support. Understanding these coping strategies and identity negotiation mechanisms highlights some unintended consequences on residents' well-being, such as the importance of standardizing how the service is organized because it provides a stable framework, or the importance given to the well-being of all stakeholders (other consumers, staff) as a result of the community living situation.
\end{abstract}

KEYWORDS: Vital service, Service captivity, Coping strategies, Elderly, Nursing home, Food, Well-being

TO CITE: GUILLEMOT, S., DYEN, M. AND TAMARO, A (2022), VITAL SERVICE CAPTIVITY: COPING STRATEGIES AND IDENTITY NEGOTIATION, JOURNAL OF SERVICES RESEARCH, 25(1), 66 - 85

Global population ageing is a challenge for our societies. The care-for-the-elderly market is growing due to the concomitant effect of longer life expectancy, physical and/or cognitive diseases that become increasingly serious as people grow older (and thus heighten dependency), and the geographical remoteness of relatives (Drolet, Schwarz and Yoon, 2011). Against such a background, many service providers offer solutions to improve the living conditions and autonomy of increasingly dependent elderly people (Moschis, Mosteller and Fatt, 2011). In particular, improved quality of care and higher safety standards put in place by the hospital and nursing home sectors lead to the emergence of more rules and standards (Bowblis and Ghattas, 2017). An unintended consequence of this is that the proliferation of standardized procedures (e.g. safety and quality requirements) has shifted the focus from care to health and safety (e.g. more time spent cleaning after meals) at the expense of residents' needs. In addition, increasingly restrictive budgetary constraints generate many critical situations such as staff and equipment shortages. In this context, staff must find a balance between managerial and professional solutions, developing new work routines according to new standards of acceptability. This fosters feelings among staff of dissatisfaction and despondency with the working conditions (Desai, 2012; Sebastiano et al., 2017), which in turn affect the residents' quality of life (Marquier et al., 2016). Residents are frequently subjected to dehumanizing service interactions (Grenade and Boldy, 2008; Westin and Danielson, 2007) and opinion surveys indicate that older people would prefer not to have to use such services in the future (Donnely et al., 2016). 
These situations are characteristic of "negative services" and "service captivity". A negative service is one that consumers would rather not use and that generates negative affects (Miller, Kahn and Luce, 2008). Service captivity occurs when consumers need to use a service but their options are limited. As Rayburn, Mason and Volkers (2020, p.163) stated: "in captive contexts, consumers feel powerless and out of control; they have no voice in the service and they have no choice in terms of both shaping the process and exiting the provider. They feel uninformed and disconnected. Ultimately, this leads to heightened consumer vulnerability and challenging interactions with service providers and processes. Feelings of vulnerability then reinforce dependency and perceived captivity, resulting in a negative service spiral". When the captivity situation lasts over time, people must cope with these negative feelings over long periods, particularly as regards social and/or health concerns (Miller, Kahn and Conant, 2009). This does not mean that these consumers no longer experience negative emotions and vulnerability, but that they have simply learned to tolerate the situation, to "live with it" (Singh and Duque, 2012). In reality, there are several types of service captivity with different possible resolutions. Rayburn, Mason and Volkers (2020) identified multiple service captivity archetypes (physical, social, contractual, monopoly captivities, etc.), each with specific consumer needs, temporal aspects, and market and governmental structures affecting the power-dependence relationship between consumer and provider. In the most serious circumstances, doing without captive services means a decline in health, or loss of vital resources, or daily living necessities such as food or housing (Rayburn, Mason and Volkers, 2020). A better understanding of the coping process can lead to improved services and reduce consumers' feelings of vulnerability, and various studies in the literature have examined how individuals cope with a service. There are two different research streams: the first focuses on the service experience itself, and the second on the consequences of using the service in daily life. The present study expands on this and contemplates situations of when life is at stake and exiting the service is not a viable option, such as in the case of people with long-term chronic diseases or for certain social services such as assistance at mealtimes. The service becomes a non-negotiable part of a person's life and they must then reorganize their personal identity to integrate it into their sense of self. Successful integration is an important step as it allows people to give meaning to events, to assimilate them, and to become more accepting of them, all of which are integral parts of eudaimonic well-being. Eudaimonic well-being is related to and depends on the person's feelings of fulfilment (Sharma et al, Conduit and Hill., 2017).

The present paper examines this problematic in the context of food in nursing homes through several qualitative data collections conducted in situ (semi-directive interviews, focus groups, participant observations and micro-interviews). It will address two questions. The first one is: "What coping strategies do people implement to cope with vital service captivity?" Data analysis showed that coping with a vital service is not a single-factor phenomenon as residents used multiple coping strategies in several areas: routinization (enduring the nursing home's routine), socialization (socializing with other actors), and assimilating the social role of dependent person. The results also indicated that coping with vital service captivity is a differential process. For example, a person may try to engage in the institution's routine while at the same time trying to disengage from social relationships, or vice versa.

The second question is: "What are the underlying identity negotiation mechanisms that lead people to adopt the implemented coping strategy"? Findings show that implementation of a coping strategy is a process based on a balance between "disengagement" and "engagement" that takes into account not only the person's previous life trajectory, future prospects and interpersonal comparisons, but also the changes in their personal skills and capabilities, and social support. 
Gaining an understanding of these coping strategies and identity negotiation mechanisms uncovered some unintended consequences on the well-being of the residents. For example, residents can value a type of organization that is scheduled, standardized and limited in choice as it provides a stable framework during the transition period from life in their home to the nursing home in which their living habits are disrupted.

In the final part of the paper, the results will be discussed from a Transformative Service Research (TSR) perspective to suggest action levers designed to facilitate coping with vital service captivity. More specifically, these suggestions aim to limit the negative, unintended consequences of collective elderly care (e.g. by raising awareness of "forced" social comparisons caused by the cohabitation of people with various dependency situations) and to increase well-being among this population (e.g. by offering future time horizons for everybody, including frail elderly people).

\section{THEORETICAL BACKGROUND}

\section{Defining vital service captivity}

A vital service is one that individuals use to fulfil their basic needs (e.g. food, healthcare, shelter). Vital service captivity occurs when individuals can no longer attend to their basic needs on their own and have no choice but to delegate them to the market. As this concerns the social and/or health fields, the market is government-regulated with strict procedures. This has led to a quasi-monopolistic situation with very few suppliers and a significant lack of information on service quality (Mittelstaedt, Duke and Mittelstaedt, 2009), in turn increasing consumer vulnerability and captivity. Consumers are in the position of having to endure the service or do without it. The present study contributes to the captive services literature by extending the captive situation archetype identified by Rayburn, Mason and Volkers (2020). More specifically, it will expand on this archetype for when exiting the service is not an option because "doing without" would cause a vital risk (vital service captivity). This is the case of health services for long-term illness, but it can be extended to social services for the most disadvantaged members of society who face chronic economic vulnerability (housing, food, etc.). Consumers must therefore learn to live with vital service captivity, but this does not mean that they are no longer vulnerable, they have just learned to accept it (Miller, Kahn and Conant, 2009).

\section{Enduring vital service captivity}

Coping strategies are considered to be a set of efforts to reduce or endure sources of stress, diminish negative emotions, and improve well-being (Lazarus and Folkman, 1984). A distinction is made between primary (problem-focused) and secondary (emotion-focused) coping strategies (Lazarus and Folkman, 1984). Primary coping is when an individual attempts to change their environment so that it corresponds to their goals and desires, while secondary coping is when an individual attempts to accommodate the self in a given environment by changing their beliefs, hopes, goals and interpretations, and thereby changing their appraisal of the situation.

The literature reports two approaches that are used to gain a more in-depth understanding of the coping strategies consumers implement to deal with a vital service captivity situation. 
A first line of research focuses on the service experience, and through it, on the satisfaction, quality and well-being of vulnerable consumers (Ostrom et al., 2015). For the social or healthcare consumer, their experience is exacerbated by the vital need and other factors such as power asymmetry, lack of expertise (Anderson et al., 2013), and sometimes lack of awareness of consumer rights (Hare, Law and Brennan, 2013). Consumers are therefore highly sensitive to the service delivery process, and in particular to the social aspects and relationships with the service providers (Morgan and Rao, 2006; Miller, Kahn and Luce, 2008). This explains why studies in a healthcare context have shown that vulnerable consumers regard quality to be just as important as reliability in the relationship with their physician (e.g. Otalora et al., 2018). For example, Bomhoff and Friele (2017) showed that some nursing home residents tended not to "complain" about the service, thinking that this would lead to undesirable social consequences that would outweigh any potential benefits of complaining. In this context, consumers are likely to use the emotion-focused strategy to cope with an attempt to restore perceived control over the situation. One way of doing this is to perceive the situation as transitory. For example, Rayburn (2015) observed that individuals who had been using food banks for several years regarded this as a temporary situation. Individuals can also regain control by accepting the situation, believing that it is the best option (Fliess and Volkers, 2020). Another strategy is to shift responsibility for the situation onto others, be it the provider, the "system", or fate (Rayburn, 2015; Fliess and Volkers, 2020). However, for vital consumer services, consumers can use more "active" (problem-focused) strategies. Echeverri and Salomonson (2019) studied implicit/explicit articulation of needs and proactive/reactive interaction with the service provider among disabled consumers in a mobility context.

This first approach is "time limited" and relates to the management aspect of the social and healthcare service experience, whereas the second approach relates to how the service affects patients' personal lives (Anderson et al., 2013; Rosembaum, 2015). A second line of research deals with the strategies and arrangements that consumers implement to integrate the service and their dependence on the service - into their daily lives. The main objective here is to restore normality and safety through the implementation of new routines (Phipps and Ozanne, 2017). Researchers have used several lenses such as acculturation (Davis, Mohan and Rayburn, 2017) or compliance (Spanjol et al., 2015). In this last study, the authors showed that there are different degrees of appropriating medical treatment in the context of a long-term illness, resulting in a variable adaptation depending on the time horizon adopted: daily (e.g. taking medication when brushing one's teeth), intermittently (e.g. putting medication in a weekly pill box), or rarely (e.g. breaking with routine when away from home). Family studies have also addressed the issue because the family typically forms the closest social unit outside the individual. Studies have shown how families - with a disabled child (e.g. Mason and Pavia, 2006), or a vulnerable elderly relative (e.g. Huff and Cotte, 2016; Trees and Dean, 2018) - must adapt family roles and norms (e.g. sharing out the work) as well as family rituals (e.g. changing and adapting the daily family routine to family traditions, such as vacations). In any case, research has shown that reorganizing routines tends to valorize family norms and reference points (Karanika and Hogg, 2016). People also look for help and support outside the family circle. For example, Gurrieri and Drenten (2019) showed how female breast cancer patients used social media to share their experiences of chemotherapy. This normalizes the hidden aspects of healthcare consumption experiences through healthcare disclosures (procedural, corporeal, recovery), the normalization of practices (providing learning resources, problematizing mainstream recovery narratives), and the search for forms of online social support. Social support increases the independence of vulnerable consumers (Beatson et al., 2020) and fosters resilience (Hutton, 2015). 
In summary, previous research has considered strategies for coping with vital service captivity as "time limited" by studying service experiences. It has also examined how individuals integrate these experiences into their daily lives by changing their routines and/or seeking social support. The present research expands this by addressing the long-term perspective of vital service captivity situations that are permanent and have no possible exit. It is important to study this because of the special efforts that must be made to enable people to cope with daily and long-term recurrences - the service is part of the consumer's life and, in this sense, must be assimilated into their sense of self and life projects.

\section{Understanding the identity negotiation mechanisms that underlie coping strategies}

To understand how a person assimilates the service into their sense of self, the article focuses on the process of identity negotiation. It adopts the central premise of the life course paradigm which states that development, stability and changes in patterns of thought and action do not occur in a vacuum, and past experience shapes elderly people's identity (Moschis, 2019). Thus, how somebody experiences, interprets and responds to life events at a given point in time and copes with them over time, depends on a process of negotiation between the present circumstances, the past self and the projected future self. Elderly people are particularly subject to this negotiation process. For this particularly vulnerable population group, identity threats are multiple, varied, and particularly challenging. Many objective (e.g. physical and cognitive decline, death of loved ones) and subjective (e.g. perspective of a limited future) events act as reminders of the nearness of death and generate a process of identity negotiation. On the one hand, this negotiation is accompanied by the distancing of the elderly person from other members of society. Elderly people find themselves in a social system that takes away their social roles and, at the same time, they are faced with a decrease in their vital energy which ultimately redefines them and disengages them from the outside world (Cumming and Henry, 1961). This "disengagement theory" is often used to explain why some elderly people prefer to live in the past, in their memories, rather than to seek out new experiences (Vercauteren and Hervy, 2002). On the other hand, the ageing process is not only synonymous with loss, it also involves the enhancement of capacities and skills (e.g. wisdom, practical experience and knowhow) and the gaining of new social roles (Twigg, 2004). Thus, "successful" ageing requires a proactive attitude through ongoing involvement, which compensates for the loss of some previous social roles through intensifying and creating others (Havighurst, 1963 - "Activity theory"). Elderly people must adopt a dynamic perspective by constructing and adjusting their identity at a point that lies somewhere between these two opposing representations of old age - ageing adults withdrawn from society versus ageing adults with social interactions and activities. In other words, these adults are in a perpetual identity negotiation process between who they think they are and the social identity assigned to them (Barnhart and Peñaloza, 2013). Consumption and especially service experiences are social situations in which these differences in perception come to the fore (Schau, Gilly and Wolfinbarger, 2009) and can generate feelings of unease (e.g. Grougiou and Pettigrew, 2011; Wetlé, 2019).

This view of identity negotiation as the search for balance between two opposites can easily be connected to coping strategies and well-being issues. "Disengagement" corresponds to emotion-focused strategies, for example, coping with the ageing process by no longer seeking to influence the outside world and even detachment from it, whereas "engagement" corresponds to problem-focused strategies, for example, becoming part of the social world and seeking to play a role in it. Thus, coping strategies are at the heart of the so-called successful ageing approach insofar as ageing is considered successful if it provides a satisfying life by remaining under the individual's active control. The identity-based challenge is therefore how to find a balance on this continuum, a balance where self-construction is coherent with the image and 
social values reflected in the service consumption, in accordance with personal desires and expectations (Gergen and Gergen, 2000). This is particularly in line with the eudaimonic approach to well-being that is related to a person's feelings of fulfilment (Sharma et al., 2017). In this respect, successful ageing involves giving meaning to events that are connected to the sense of self (Haber, 2006). In line with Butler's insights (1963), some researchers consider that an individual successfully copes with events when they can give them meaning and blend them into a coherent life history that is their own (e.g. McAdams, 2001; Haber, 2006; Guillemot and Urien, 2016).

To summarize, vital service captivity occurs when individuals have no choice but to turn to the market to fulfil their basic needs and, as a result, feel vulnerable and become dependent on the service. The literature shows how consumers "live" the service experience and/or how they integrate it into their daily routine to find a sense of normality. However, these studies do not take into account the long-term perspective inherent in a vital service from which there is no exit. The contribution of this paper is that it focuses on the situations when consumers must, out of necessity, integrate the service into the sense of self forever. This durability, or even definitivity, is important because successful integration enables people to give meaning to events, to assimilate them and become more accepting of them, which is an integral part of eudaimonic well-being.

This paper therefore adopts a holistic vision and seeks to: (1) identify strategies for coping with vital service captivity and (2) present the identity negotiation mechanisms that lead people to choose one strategy over another. Understanding how individuals carry out this identity negotiation and how it underpins their coping strategies can help shed new light on the literature dealing with permanent and daily vital service captivity and well-being/accomplishment issues. Furthermore, the study provides vital service providers with the leverage to facilitate service captivity coping strategies.

\section{METHODS}

\section{Study context: food in nursing homes}

Nursing home food provides a useful context to study identity negotiation processes. It corresponds to vital service captivity as moving into a nursing home reflects a long-term care need, a necessity rather than a choice (Sury et al., 2013). Residents can feel powerless and dependent on the daily nursing care process; they have lost their independence because they have to wait for help and support. This transition to long-term care can therefore lead to identity reshaping (Riedl, Mantovan and Them, 2013), which may contribute to the onset of depression among new residents (Choi, Ransom and Wyllie, 2008). Food is an important aspect of ownership in this new living space since it is part of a daily activity that both punctuates the day and is a social moment (Guérin, 2016). Within this context, the mealtime in nursing homes could be considered a meaningful activity in the elderly residents' lives (Bundgaard, 2005). Residents, or consumers, cope with these multiple constraints according to their personal identities: their personal tastes and previous eating habits (Timko and Moos, 1989) and the social aspects associated with their place in the nursing home (Verleye, Gremmel and Rangarajan, 2014). 


\section{Study design}

The study was conducted over a period of six months in a state medical centre that manages six nursing homes with approximately 100 places each. The medical centre was located in a medium-sized city in France. The study was carried out in collaboration with each medical centre team, in particular the supervisory teams (hospital managers, nursing home managers, health managers), healthcare teams (nurses, caregivers, doctors), and catering teams (head of the central kitchen, hospitality staff managing the daily service, dieticians). The medical centre selected three nursing homes for the study. The first two (TC and KR) were located in the city centre and had 116 and 108 residents respectively at the beginning of the study. The third (LE) was out of town and located by the sea; 97 people lived there. All the preparatory meetings for the study were held in the nursing homes so that the research teams could immerse themselves in each home's atmosphere.

Figure 1. Data set

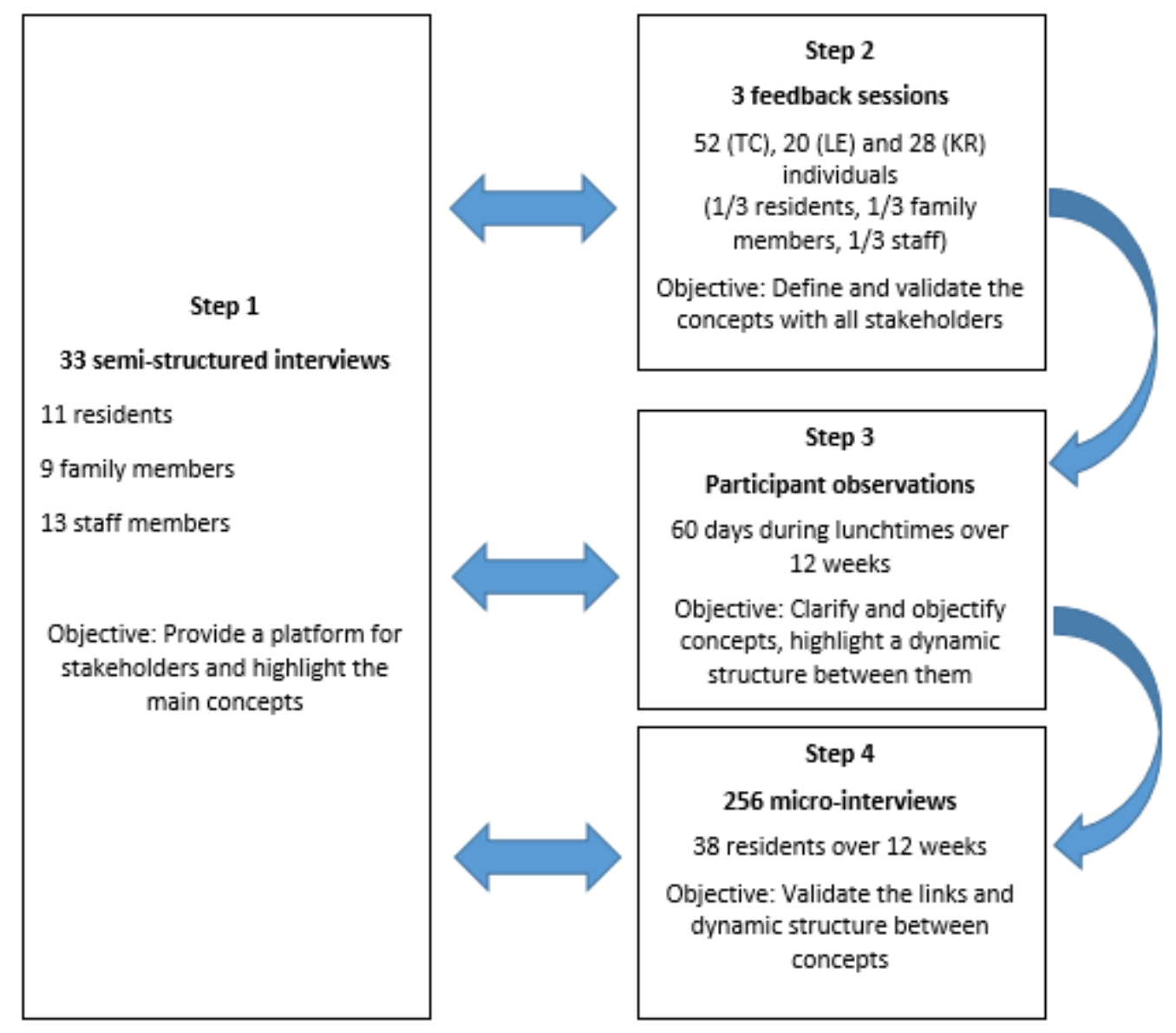

The research methodology had 4 steps (Figure 1):

1. 33 face-to-face, in-depth semi-structured interviews with 11 nursing home residents with physical limitations, 9 family members of residents with dementia, and 13 nursing home members of staff.

2. Feedback sessions to report findings (focus groups) with panels comprised of all actors (3 sessions with a total of 110 people - residents, families and staff) to compare our analyses to each actor's point of view. 
3. Participant observations during weekday lunchtime meals for 12 weeks (60 days), which allowed us to clarify and objectify the data obtained during the interviews and focus groups.

4. 256 micro-interviews with 38 residents conducted at the same time as participant observations to follow participants' evolution throughout the 12-week period.

Step 1 was the core of the data collection as its objective was to question residents about their experiences in the nursing home. The other steps complemented this data, helping us to interpret the results through feedback from the different actors - residents, family members and staff (Step 2), to gain a better understanding of the functioning of the services and the hidden and non-verbal phenomena (Step 3), and a more detailed understanding, gained over several meals, of how the residents felt (Step 4). In this respect, the data collection was triangulated in different ways, and our study consisted of a genuine immersion in the object under study.

\section{Semi-structured interviews}

Data collection. The information was collected through semi-structured interviews to enable people who were directly concerned by nursing home food to talk freely about their experiences and feelings about it (Table 1). An interview guide comprising three main themes was drawn up to include the description of mealtimes, the place of food in the daily life of the nursing home, and the relationship between well-being and eating well. Establishing anchor points in everyday experiences is a "facilitating" technique used to initiate discussion in studies with elderly people (Lambert-Pandraud and Laurent, 2010). In relation to the research topic, participants were progressively questioned about their life and diet before they lived in the nursing home. Although the study focused on resident experiences, it seemed appropriate to take into account the opinion of all stakeholders involved in the life of the nursing home who co-construct the residents' care, i.e., families and nursing home staff (Kristiansen et al., 2015; Verleye, Gremmel and Rangarajan, 2014). In addition, interviewing the families and staff meant that the viewpoint of many residents with cognitive dementia, severe memory disorders, or who were unable to speak, was indirectly expressed.

First, 11 volunteer consumer-residents participated in the study. These participants presented no significant cognitive impairment and were able to participate in a 30- to 60-minute interview. They comprised six men and five women with an average age of 83.64 years (standard deviation: 7.51 years), and an average length of stay in the nursing home of 3.5 years (standard deviation: 3.8 years). These participants had physical problems that impacted their food behaviours: some were partially paralysed and needed the staff to help them get up and move around (Residents no. 7 and 11) or cut up their food (Resident no. 5), whereas others had Parkinson's disease and needed assistance with their meals (Resident no. 10).

In addition, we also asked 9 relatives of residents (with significant cognitive degeneration sometimes accompanied by inappropriate food behaviours and/or lack of communication) for their point of view. One of the residents, for instance, would only eat if spoon-fed (Family member no. 13). The family's perspective here was essential because they were directly involved in the resident's daily life and could interpret their physical and emotional reactions (Verleye, Gremmel and Rangarajan, 2014). They were recruited by the teams in the nursing homes over the course of the study and provided insight into the situation of nine residents with an average age of 80.78 years (standard deviation: 8.57 years) and an average length of stay in the nursing home of 2.66 years (standard deviation: 3.3 years). These nine relatives were the spouses (two cases), children (five cases) or siblings (two cases) of the residents in question. 
Finally, nursing home staff involved in mealtimes (catering staff, caregivers and nurses) were also interviewed. In addition to their technical caregiving skills, they constantly interacted with the residents and their families and set the timing of the meals (Gherardi and Rodeschini, 2015). Thirteen nursing home staff answered the questions in the interview guide. To diversify the viewpoints, we interviewed staff members working in several different categories: four catering employees who prepared and served meals, five caregivers who helped residents to eat during mealtimes, and four nurses in charge of nutrition-related medical aspects and who also assisted during mealtimes. These 13 members of staff had an average of 13.91 years' experience in the profession (6.2 years in the nursing home under study).

Data analysis. The interviews were recorded (over 24 hours of conversation) and then fully transcribed (580 pages). A thematic content analysis was conducted. The verbatim transcripts were coded as closely as possible to the data and in parallel by two of the team's researchers (first and third authors). The work then involved gradually increasing the abstraction level. Little by little, the reported coping strategies were aggregated into three main categories. The first one relates to coping with the nursing home's routine (which we called routinization). It includes the times when respondents talked about how they felt about the material conditions of the service such the dining room set-up, meal times, or the menu itself. For example, Anne (Resident no. 6) talks about the portion sizes "It's not that its bad, they make an effort with the meals. The problem is with the size of the portions. They give us far too much to eat and we don't get any say in it. It's the doctors who decide how much we get and that's it. I always leave over half of it and it's a shame because it's a waste. But it's like that and there's nothing we can do about it'. The second category of coping strategy relates to adaptation to social interactions (which we called socialization). This category is comprised of the times when respondents talked about their actions and interactions with the residents they share mealtimes with. Raymond (Resident no.7) is a good example: "From day one I've eaten at the same table with the same people. That's where they put me when I first got here and I've not moved since. [...] the meal times are often very quiet; I don't say much myself but I do a lot of listening". The third category is related to the assimilation of the social role of dependent person (which we called assimilation of a new social role). This category is comprised the times when respondents mainly talked about the issues of dependence and its associated images and projections. Huguette (Resident no. 9) illustrates this point: "Here, I spend a lot of time around people who are not in their right mind anymore and that makes me really sad. This retirement home has made a mistake by doing that, we're all mixed together regardless of how dependent we are, and yes, it scares me to see some things and to see how we may become". The other major themes mainly concerned non-meal-related social aspects in the home, former lifestyle habits, the circumstances that led individuals to go into a nursing home, the dependence experience and the opinion of "others", and bearings on health and future projects, etc. 
Table 1. Respondent Information

\begin{tabular}{|c|c|c|c|c|c|c|c|}
\hline \multicolumn{8}{|c|}{ Residents } \\
\hline no. & Respondent & Gender & Age & $\begin{array}{l}\text { Nursing } \\
\text { home }\end{array}$ & $\begin{array}{l}\text { Seniority } \\
\text { (year) }\end{array}$ & Former occupation & $\begin{array}{l}\text { Duration } \\
\text { (min) }\end{array}$ \\
\hline 1 & René & $\mathrm{M}$ & 91 & $\mathrm{LE}$ & 1 & Factory worker & 24 \\
\hline 2 & Thérèse & $\mathrm{F}$ & 77 & LE & $<1$ & Caregiver & 35 \\
\hline 3 & Paulette & $\mathrm{F}$ & 84 & LE & 11 & $\begin{array}{l}\text { Factory worker/housewife/factory } \\
\text { worker }\end{array}$ & 22 \\
\hline 4 & André & M & 93 & LE & 1 & Subway driver, then engineer & 54 \\
\hline 5 & Colette & $\mathrm{F}$ & 78 & LE & 4 & Butcher & 63 \\
\hline 6 & Anne & $\mathrm{F}$ & 74 & KR & 2 & Ceramics factory worker & 46 \\
\hline 7 & Raymond & M & 93 & $\mathrm{KR}$ & 10 & Livestock farmer & 28 \\
\hline 8 & Georges & M & 88 & KR & 2 & Carpenter joiner & 48 \\
\hline 9 & Huguette & $\mathrm{F}$ & 72 & $\mathrm{TC}$ & 5 & Sales representative & 57 \\
\hline 10 & Robert & M & 83 & $\mathrm{TC}$ & 1 & Building trade & 26 \\
\hline 11 & Jean & M & 87 & $\mathrm{TC}$ & $<1$ & Railway worker & 42 \\
\hline \multicolumn{8}{|c|}{ Family } \\
\hline no. & Respondent & Gender & Age & $\begin{array}{c}\text { Nursing } \\
\text { home }\end{array}$ & $\begin{array}{c}\text { Seniority } \\
\text { (year) }\end{array}$ & Resident's former occupation & $\begin{array}{c}\text { Duration } \\
\text { (min) }\end{array}$ \\
\hline 12 & $\begin{array}{l}\text { Marcel's } \\
\text { daughter }\end{array}$ & $\mathrm{M}$ & 93 & LE & 2 & Road mender & 41 \\
\hline 13 & Richard's wife & M & 74 & LE & $<1$ & Engineer & 43 \\
\hline 14 & $\begin{array}{l}\text { Maurice's } \\
\text { daughter }\end{array}$ & M & 77 & $\mathrm{LE}$ & $<1$ & Restaurant owner & 28 \\
\hline 15 & $\begin{array}{l}\text { Josette's } \\
\text { daughter }\end{array}$ & $\mathrm{F}$ & 77 & LE & $<1$ & Canteen worker & 53 \\
\hline 16 & $\begin{array}{l}\text { Jeanne's } \\
\text { daughter }\end{array}$ & $\mathrm{F}$ & 94 & $\mathrm{KR}$ & 2 & Cleaner in a school & 56 \\
\hline 17 & $\begin{array}{l}\text { Marthe's } \\
\text { husband }\end{array}$ & $\mathrm{F}$ & 80 & $\mathrm{KR}$ & 1 & Hotel industry & 22 \\
\hline 18 & Henri's sister & M & 75 & $\mathrm{TC}$ & 11 & Railway worker & 47 \\
\hline 19 & $\begin{array}{l}\text { Simone's } \\
\text { daughter }\end{array}$ & $\mathrm{F}$ & 87 & $\mathrm{TC}$ & 4 & Council worker & 34 \\
\hline 20 & Denise's sister & $\mathrm{F}$ & 70 & $\mathrm{TC}$ & 1.5 & Nurse & 43 \\
\hline \multicolumn{8}{|c|}{ Staff } \\
\hline no. & Respondent & Gender & Age & $\begin{array}{c}\text { Nursing } \\
\text { home }\end{array}$ & $\begin{array}{c}\text { Seniority } \\
\text { (year) }\end{array}$ & Occupation (number of years in the job) & $\begin{array}{c}\text { Duration } \\
\text { (min) }\end{array}$ \\
\hline 21 & Nathalie & $\mathrm{F}$ & $35-45$ & $\mathrm{LE}$ & $<1$ & Nurse (5 years) & 45 \\
\hline 22 & Sylvie & $\mathrm{F}$ & +45 & LE & 12 & Caregiver (20 years) & 20 \\
\hline 23 & Céline & $\mathrm{F}$ & $35-45$ & LE & 1 & Caregiver (10 years) & 53 \\
\hline 24 & Camille & $\mathrm{F}$ & $25-35$ & LE & 1 & Nurse (7 years) & 43 \\
\hline 25 & Julie & $\mathrm{F}$ & $25-35$ & LE & $<1$ & Caregiver (15 years) & 51 \\
\hline 26 & Audrey & $\mathrm{F}$ & $35-45$ & $\mathrm{KR}$ & 4 & Catering employee (4 years) & 53 \\
\hline 27 & Karine & $\mathrm{F}$ & $25-35$ & $\mathrm{KR}$ & 8 & Catering employee ( 8 years) & 47 \\
\hline 28 & Brigitte & $\mathrm{F}$ & +45 & $\mathrm{KR}$ & 23 & Caregiver (35 years) & 45 \\
\hline 29 & Caroline & $\mathrm{F}$ & $35-45$ & $\mathrm{KR}$ & 1 & Nurse (12 years) & 80 \\
\hline 30 & Nathalie & $\mathrm{F}$ & +45 & $\mathrm{TC}$ & 15 & Caregiver (15 years) & 45 \\
\hline 31 & Sandrine & $\mathrm{F}$ & $35-45$ & $\mathrm{TC}$ & 11 & Catering employee ( 15 years) & 70 \\
\hline 32 & Aurélie & $\mathrm{F}$ & $35-45$ & TC & 4 & Catering employee (17 years) & 46 \\
\hline 33 & Michèle & $\mathrm{F}$ & +45 & $\mathrm{TC}$ & $<1$ & Nurse (19 years) & 45 \\
\hline
\end{tabular}

Note. $\mathrm{M}=$ Male; $\mathrm{F}=$ Female; $\mathrm{LE}=$ Nursing Home $1, \mathrm{KR}=$ Nursing Home 2, $\mathrm{TC}=$ Nursing Home 3 


\section{Feedback session}

This second step of the study was carried out to validate the themes of the first analysis and to contextualize it with as many stakeholders as possible involved in nursing home food. It was carried out in each nursing home and consisted of public feedback sessions in the form of focus groups in which these first analyses were presented. These feedback sessions were announced in the nursing homes a few weeks before the date and brought together 52 (TC), 20 (LE) and 28 (KR) people: in each workshop, approximatively one third were residents, one third families and one third staff. After briefly presenting the main themes that had emerged from the interviews, the research team gave the floor to the room. The discussions lasted between 90 minutes and two hours. The various comments and reactions were recorded in field notes. This step was particularly enlightening for giving meaning to the data. For example, it had been noted in step 1 that mealtimes were often very quiet. The residents taking part in the feedback sessions explained: "that's to be expected seeing as the people I eat with are half deaf!", "nothing much happens here so there's nothing much to talk about", "the only thing we've got in common is that we're there at the same time", etc. As the families and members of staff were also taking part in these sessions, they were able to provide further details, or to correct certain things or put them into context. Ultimately, this step made it possible for the themes that had emerged in the coding of the interviews to be validated and clarified by the main stakeholders (residents, families and staff). It also confirmed the convergence of viewpoints between the different stakeholders.

\section{Participant observations and micro-interviews}

In the third step, researchers from the team conducted participant observations in each nursing home. In the preparatory step, the researcher-observer was present from 7 am to $1.30 \mathrm{pm}$ and accompanied a member of staff in the caregiving activities and the serving of breakfasts and lunches. Then, after the interviews, researchers were present from Monday to Friday for 12 weeks (60 days). They helped staff with the meals (11am: preparing the room, heating the meals and welcoming residents, 12am: service, cleaning the room, 1pm: end of service). The lunchtime service was selected for logistical reasons as it was easier for the staff to accommodate us at that time. The researchers took field notes of their observations and reflections.

The fourth step ran in parallel with the third step. It consisted of micro-interviews with residents. Following the participant observations, the researchers talked to the residents in their own environment (i.e., their room). The idea was to identify a panel of residents to follow their development throughout the 12-week period. The discussions focused on three points: routine and appreciation of meals, socialization with other residents, and social position towards the staff, in other words, the adaptation areas that had emerged from the thematic content analysis. The discussions were not recorded but field notes were taken. The idea was to interview each resident once a week (whenever possible) to monitor their feelings over the 12-week period, but in practice this was not possible for various reasons (resident busy, absent, tired, etc.). In the end, regular discussions were established with 38 residents for a total of 256 microinterviews (between 2 and 11 discussions per respondent - out of a possible 12 - for an average of 6.73 discussions per respondent). These exchanges were instrumental in building a relationship of trust with the residents, who openly shared their thoughts and feelings. For example, one resident talked about how her state of health was changing and how this affected her relationships with others, at mealtimes in particular: "I don't really like to have a conversation with anybody anymore because I'm afraid I won't be able to hear what they say". Another resident told us about her interactions with the staff over time: "the people on today 
[serving the meals] aren't my favourite members of staff, especially one lad...it can get a bit tricky with him sometimes, we don't really get along".

These two additional steps were mainly conducted by a third researcher who had not participated in the first two steps (the second author). Discussions involving the whole research team and comparisons of the analyses of the two methods for accessing real-life situations thus constituted a kind of "second-order" analysis (Gioia et al., 2013). It allowed us to clarify and objectify the data obtained during the step one interviews. For example, we were able to affirm the importance of certain themes that might appear insignificant in the discourse (e.g. solidarity between residents). This step also made it possible to update and discuss the links between the themes, thus giving the data a dynamic structure. For example, we could determine how eating lunch with people that have various cognitive and/or physical disabilities engenders a process of socially comparing one's own situation with that of one's fellow diners, and how this comparison process will lead people towards disengagement or engagement strategies depending on whether their personal situation is perceived as more unfavourable or favourable, respectively. Thus, a conceptual framework was gradually developed that interlinks the different coping strategies and the underlying identity negotiation mechanisms. Figure 2 presents this framework, which is described in more detail in the next two sections.

Figure 2. Vital service captivity coping process

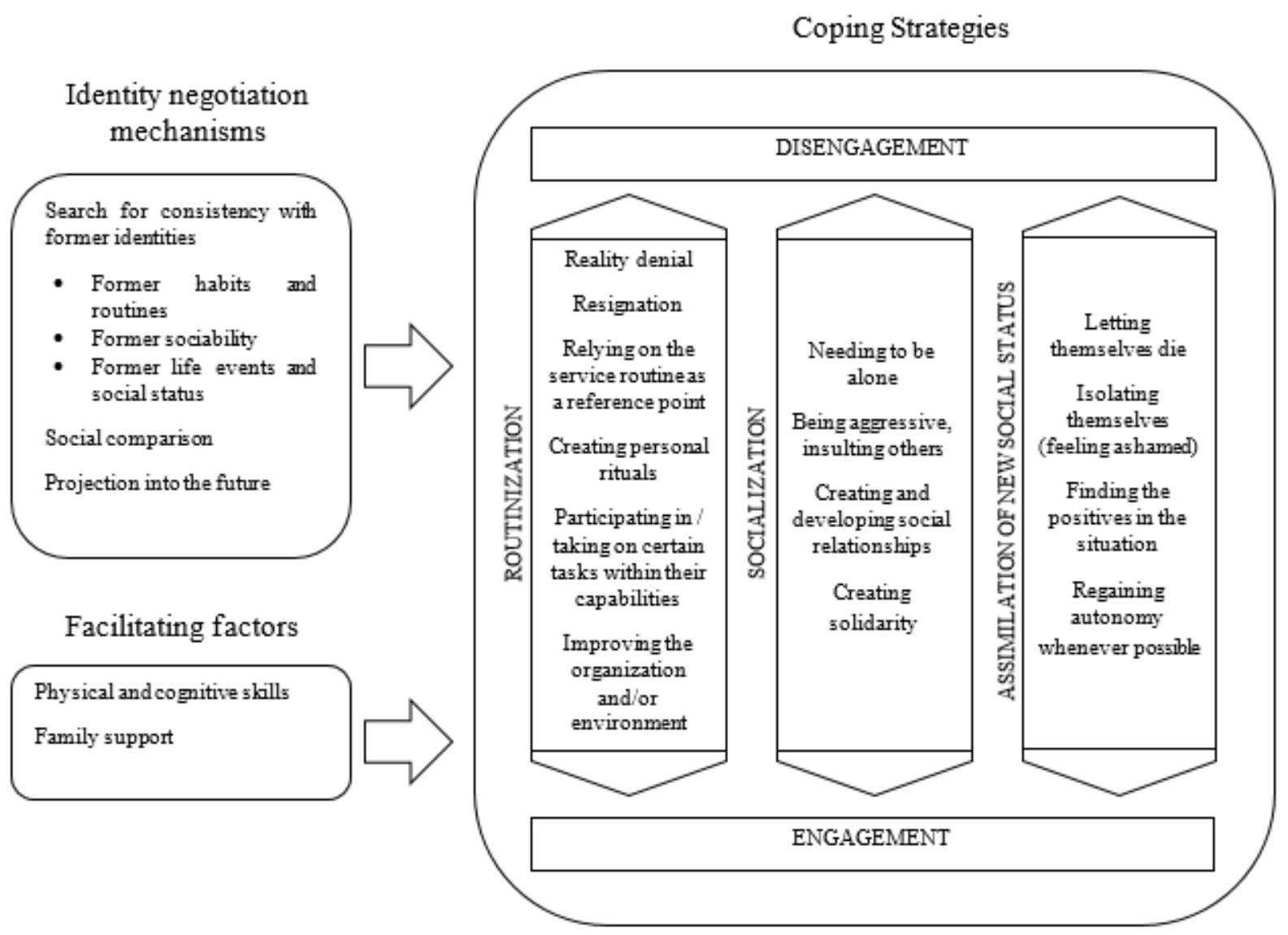




\section{COPING WITH VITAL SERVICE CAPTIVITY}

Data analysis showed that coping with a situation of vital service captivity does not depend on one single factor. Our findings highlight three distinct coping areas: (1) routinization (individuals obliged to cope with the service's routines and material conditions), (2) socialization (individuals obliged to cope and interact with other consumers who use the service), and (3) assimilation of a new social role (vital service consumption that involves adopting and integrating the social status of a dependant person). The results highlight that consumers adopt distinct and non-related coping strategies in each of these three areas. The following paragraphs detail the three coping areas and present the strategies implemented to deal with them. Each strategy is illustrated by quotes from the semi-structured interviews, put into perspective with the different data collected (feedback sessions, observations, microinterviews).

\section{Routinization}

When individuals move into a nursing home they must come to terms with the characteristics - and constraints - inherent in the organization of the service. For nursing homes, logistical, organizational and health constraints are such that it is impossible to cater for individual habits. Our observational data show that the staff timetable dictates the routine and has an impact on the residents' day. For instance, lunch must be finished by $1 \mathrm{pm}$ because of the staff changeover time, whereas in the evening, only two nurses are responsible for 35 residents and people who require assistance with eating must wait until the care workers are available, their meal often sitting on the table and getting cold in front of them. All these constraints involve optimizing/rationalizing the time spent with each resident as they all gather in the same place at the same time. As a result, residents must give up their own routine to cope and comply with that of the facility. We found that residents adopt different strategies ranging from disengagement (reality denial) to engagement (attempts to improve the service organization and environment), with intermediate positions in between where which individuals create personal rituals around collective routines.

Reality denial. This strategy is frequently adopted in the first few weeks after arrival in the nursing home. The resident does not try to adapt because they are convinced that the situation is temporary, and that they are going to leave: "Some people don't want to eat. One person, for example, categorically refuses to eat. She says she's going to eat at home. In fact, she thinks she's going to go home. There are a lot of people who think they're here for a day or two like in hospital. It's quite something" (Staff member no. 24). This attitude is temporary and residents gradually get used to the idea that the situation is a long-term one.

Resignation. This strategy is adopted when individuals who find they have no control over the service organization remain silent and end up accepting the conditions, even if they do not like them, with a sense of fatalism. For example, Colette (Resident no. 5) does not like certain meals but prefers to keep quiet rather than enter into a negotiation process: "I don't eat the omelettes. I don't say anything because they'd want to give me something else, a slice of ham, and I don't want that either. No, no, no, I take it, I don't eat it, but I don't say no to the girls [the staff]." The "it doesn't suit me but I'm not saying anything" stance is very common. Residents accept the service because they are convinced that there are no other solutions. But acceptance does not necessarily mean adherence. We identified that acceptance comes mainly from a better understanding of the facility's organization and operating constraints: "We have 
to understand that we're in a community, that we can't eat in this system like we did at home. It's impossible" (Resident no.9).

Relying on the service routine as a reference point. To reduce vulnerability, most residents endorse the facility's routine and even consider it as a reference point. Mealtimes become markers in the day and give it a sense of rhythm. As André (Resident no. 4) points out: "Well, I don't go hungry here [...] It's not a necessity, it's a routine. I don't know what there'll be at lunchtime and, well, I eat whatever there is. I get used to whatever we eat here, but I'm not going to be fussy. It's a routine to eat what we're served."

Creating personal rituals. Within the structure's predefined framework, some residents may introduce moments of perceived freedom, i.e., making adjustments that do not affect the organization of the structure itself. This freedom can materialize through the adoption of personal rituals such as eating a piece of chocolate (Resident no. 4; Family no. 16) or an apple (Resident no. 7) in the evening before bedtime. In all cases, these personal rituals created around collective routines provide residents with a little more ownership of the place: "It gives us the impression of being at home to a small extent. We talk about it a lot among ourselves, you know, because the feeling of not being at home is what's difficult" (Resident no. 8).

Participating in/taking on certain tasks within one's capabilities. We also observed strategies whereby individuals actively participated in the service process to make themselves useful by suggesting menu ideas, for example, or helping the staff with their work: "There can also be a participatory approach with some residents wanting to help lay the table. Laying the table is a very basic task: plates, glasses, cutlery, the napkins are put out at the last minute, and also a jug of water on the table" (Staff member no. 29).

Improving the organization and/or environment. This participation rationale can be taken further when individuals seek to improve the service. For instance, some residents get involved in nursing home life by becoming a resident representative, participating in "menu committees" to give the provider feedback: "I' $m$ a member of the social life committee. I' $m$ the residents' representative. I relay what the others are thinking. There are committee meetings and I have to say what's not working and what is. It's also important to say what's going well. [And is your opinion taken into account?] Yes, there have been some improvements in the five years that I've been here" (Resident no. 9).

\section{Socialization}

In addition to coping with the service routine, our results highlighted that the social aspects of the service also create a captivity situation. Individuals with their own preferences must learn to cope with other consumers, all of whom have their own particular history and their own particular disabilities. Mealtimes are often very quiet and communication is difficult. The feedback we obtained in the nursing homes helped to explain this lack of communication. First, there is not much affinity between residents from different social backgrounds, with different experiences and sometimes with very different interests. The nursing home is the only thing that brings these people together, putting them in a situation in which they are forced to talk to each other. During the micro-interviews, respondents repeatedly stressed that "we've got nothing to talk about anyway". Second, there is the daily life in the nursing home. Not much happens there and topics of conversation are quickly exhausted. Illustrating this point, it was noted during the observation phase that most social interaction took place when the daily newspapers were delivered, an event giving residents a chance to discuss the news. Several coping strategies related to socialization were identified, from disengagement (needing to be alone) to engagement (creating solidarity). 
Needing to be alone. To avoid getting into uncomfortable situations, some residents sought to escape from social relationships as much as possible, adopting a disengagement type strategy: "I don't talk to anyone, after lunch I don't hang around, I go back to my room, watch TV, stay in the hallway, walk around, and that's enough for me. [...]. I prefer to do my own things" (Resident no. 11). Our observations show that this situation is quite common and even after several months or years of sitting down for meals together, some residents still know very little about each other's lives.

Being aggressive, insulting others. For some, withdrawal is expressed by aggression towards peers, as illustrated by this verbatim account from the sister of a resident who lost his mobility due to severe diabetes and cannot accept his disability: "He says some harsh, really harsh things to the staff ... I've tried to tell him that the staff aren't there to take his insults, but the situation just keeps getting worse. I've often told him, they're not scapegoats, just because you're unhappy it doesn't give you the right to insult them" (Family member no. 18).

Creating and developing social relationships. Some people do not run away from their peers, but deal with those present. Residents tell us that they do not choose the people with whom they share their mealtimes, but that they get used to them: "There are many people like me, they're in their chairs. They can't move [...]. Oh no, there's nothing interesting about having to stay in the same four walls. We need to see people, to talk, you know" (Resident no. 7). Residents have to deal with the other people present, which gives rise to subgroups, friendships and couples.

Creating solidarity. Even if there is no affinity between the residents, they know that they share the same dependence situation and for some this creates solidarity situations. For example, we observed situations in which people support others who do not have the same advantages as they do, such as not being allowed to eat certain foods. The staff know about these exchanges: "Some people aren't allowed to eat bread because of the risk of choking. So what happens is that a resident who's allowed to eat bread, but who doesn't, will put it in their pocket and then join the other resident in their room and give them the bread. These are the sorts of things we see" (Staff member no. 26).

\section{Assimilation of a new social status}

A final theme emerged from the data collected. Consumption of vital services leads to the assimilation of a specific social status - in this case, that of a dependent person. Within the context of a nursing home, this image is very clear. The sister of a resident who had been there for 11 years had witnessed the changes in the health of people entering the nursing home, noting that placement in a home was really a last resort. People arrive "very impaired with highly diminished physical or intellectual faculties" (Family member no. 18). While the nursing home is meant to be a medico-social facility, i.e., a living space that includes a medical care aspect, the observations and interviews clearly showed that medical care prevails over daily life. Many things in the environment remind residents of their condition as patients and/or dependants: sanitized environment, staff (including catering staff) in white coats, and the omnipresence of medication during meals: "Taking medication, that's also a big problem. When you've taken ten tablets practically on an empty stomach or at the same time as the meal, what image does that give? (Staff member no. 29). Moreover, even though relations between staff and residents can be quite good and respectful, residents are very reluctant to share their feelings and talk about the things that bother them or that could be improved. During the micro-interviews, we often heard "I don't want to be a bother" as a reason for not asking for help or expressing a preference. Consumers experience dependency as they need the staff to be able to live. To summarize, dependency and illness are a reality that emerges in the consumption of services. 
Residents must relinquish their autonomy and incorporate this new social status into their life. The coping strategies observed with regard to the inclusion of this new social status range from "final" disengagement (letting themselves die) to engagement (regaining autonomy whenever possible):

Letting themselves die. Vital service consumption is captive because there is no option to exit without a life-threatening risk. Death can thus be considered as an option to end it. Consequently, the staff reported that they frequently see what they call a "downturn", a sudden deterioration in health: "There are people who let themselves die, who refuse to eat because of depression, because of ageing, because of illness, because of difficulty in accepting admission to a care facility" (Staff member no. 29). This situation is often observed in the first few months after arrival in a nursing home.

Isolating themselves (feeling ashamed). Without going so far as to let themselves die, some residents prefer to isolate themselves and avoid social contact because they are ashamed of their condition. For example, one resident told us that he preferred not to say anything at the table because his hearing was not very good and he did not dare ask others to repeat themselves. Similarly, other residents had difficulty swallowing and ate special meals with a 'pureed' consistency, some had problems chewing and drooled profusely, and some had problems holding things and dropped their food. Thus, "for some people, eating is a chore. They can be messy eaters and the way other people look at them bothers them. In these cases, we let them eat in their room, but we try to communicate with them, try not to let them withdraw into themselves" (Staff member no. 28). In practice, we saw many situations where residents who would have preferred to eat alone are forced to eat with everyone else due to material constraints (i.e., not enough staff, not enough space). In such cases, the person tries to be as invisible as possible, avoiding the gaze of others and sometimes seeking an ally in the staff (e.g. by asking a member of staff to check that they are clean and have not spilled any food on themselves).

Finding the positives in the situation. We observed several positives, the most frequent being: feeling safer with medical staff nearby, and not needing to do any housework or cooking. For example, considering that one day she too will have to go into a nursing home, Denise's sister (family member no. 20), herself 80 years old, said: "If you have a fall somewhere [...] you could die before [someone] can get to you. At least here, you know there's a chance, if you ever fall or something happens, there's always someone here to help".

Regaining autonomy whenever possible. Despite the inherent organizational constraints that do not encourage autonomy, some residents seek to regain autonomy as soon as they can, for example, by trying to do things themselves as much as possible and only asking for help as a last resort. Others adopt more active stances. For instance, Huguette (Resident no. 9), who has lost nearly all her teeth, forces herself to chew with her gums to avoid eating pureed food: "Some people eat pureed food because they find it difficult to swallow... [...] I'll never eat pureed food, never! I have lots of problems with my teeth because I had to have my upper teeth removed, and I don't have very many of my bottom teeth left anymore either. But I chew with my gums, they're rock solid.". These postures are often a source of conflict with the staff, especially when there is a perceived health risk. The switch to pureed food is ultimately decided by the staff when they feel there is a risk of choking.

\section{Unintended consequences due to the implementation of coping strategies}

The nursing home strives to ensure resident well-being, however, sanitary, temporal and material constraints lead to the implementation of procedures that are standardized and mutualized, and it is the residents who ultimately have to cope with this constrained and non- 
personalized organization. The study identified 14 strategies for coping with nursing home food across three areas: routinization, socialization and the assimilation of a new social role. These coping processes have unintended consequences on the well-being of residents. Three elements appeared to be particularly salient.

Gradual adaptation to the institution's routine hides improvements. In the routinization area, habituation appears to be 'linear' and gradual. Residents who have been there longer report going through several phases ranging from disengagement to engagement. Paulette (Resident no. 3) who has lived in the home for 11 years is a perfect illustration of this: she has now adopted a routinization approach, providing decorations for the dining room which she made with other residents during a creative workshop (i.e., improving the environment). Before reaching that point, however, she went through several stages: first resigning herself to the situation, then starting to comply with the routine, before developing personal rituals as she became accustomed to the situation. The unintended consequence of this progressive habituation process is that any organizational changes made to improve the residents' lives had no effect, at least in the short term. What stood out from the micro-interviews was that people's opinions of the service vary very little - the same positive and/or negative appraisals arose each time, even when the menu and environmental conditions changed - it was as if residents regard the service as a whole, as a backdrop, without seeing its specific aspects on a day-to-day basis. For example, one man kept telling us the same story when, describing his day, he used the same words to refer to the meals: "reheated meal", "too much sauce", or about the atmosphere of the place: "a factory", "no soul". When pushed to talk about the meal of the day, he would say that "yes, today was fine" but very quickly returned to his general opinion. Similarly, during our observation period, tablecloths and flowers were put on the tables in one of the nursing homes (KR). The residents responded positively to this ("Oh it was a big day today"), but this did not impact - by their accounts - their overall judgement of the service provision. It was as if the respondents had an overall image of the service (of the quality of the meals, the dining room) and that this image was not impacted much by the changes made.

Social adaptation is dependent on stakeholder well-being. With regard to the other two areas of adaptation - socialization and assimilation of the new social status - adoption of these strategies never seems total or definitive and can vary from day to day, which means that a resident can change their strategy over time and nothing precludes them from moving from disengagement to engagement. The observations and micro-interviews showed us that residents react to other people's (i.e. other residents or members of staff) behaviours and well-being, and that these interactions can cause both positive and negative unintended consequences. For example, during one of our observation periods, an unintended negative consequence was observed when the service was disrupted by a resident with Alzheimer's disease who spoke loudly, repeatedly insulted another resident at her table, calling her a "liar" and a "thief", and rebuffed the staff who asked her to calm down. During the after-meal micro-interviews, there was an animated discussion among the residents whose opinions ranged from annoyance to sadness about the ravages of the disease. We also observed the extent to which staff moods can be communicative and spread to the residents. An example of a positive unintended consequence at one mealtime is when the staff started to hum along to the music playing in the background and did some pretend dancing; this was immediately appreciated by the residents.

These results highlight to what point the unpredictability dimension of human relations underscores to the process of coping with the service. On a more individual level, residents are highly sensitive to personal attentions and to the fact that the staff respect their personal tastes and habits. For example, during a micro-interview, one resident was very upset because her meal had just been served with "too much sauce", but she does not like the sauce and generally does not need to say so because "they" (the staff) know this. The fact that this unspoken rule 
was broken was very upsetting to her. However, we were able to observe that staff levels of attention also varied according to staffroom discussions, fatigue from being short-staffed due to absences and last-minute replacements, or after management announcements (for holidays in particular).

The three areas of adaptation are independent of each other. The above paragraphs highlight that interpersonal relations are variable over time, and that the socialization and assumption of social role coping strategies are not stable or linear over time. Routinization, however, relies on more stable parameters over time (schedules, repeated menus, etc.) and results in coping strategies that can be stable or linear. As a result, a key finding is that the three areas of adaptation identified are highly differentiated and independent of each other. In other words, residents can adopt disengagement in one area and engagement in another. For example, Georges (Resident no. 8) appreciates the facility's routine (relying on the service routine as a reference point), but not the company of other residents (needing to be alone). However, there may be some overlap between the different strategies adopted. For instance, there is some inertia to the allocated seating at the table, as this is a reference for many residents. However, this routinization does not foster socialization because although residents live together they do not necessarily have much in common.

To better understand the implementation of these strategies, it is important to examine the identity negotiation mechanisms underlying the residents' coping strategies.

\section{IDENTITY NEGOTIATION MECHANISMS UNDERLYING COPING STRATEGIES}

When moving to a nursing home, elderly people must reorganize their lifestyles according to the nursing home and the services offered. As a result, they have to reconstruct themselves individually within a new social system. The present study identified 14 coping strategies for nursing home food across three areas: routinization, socialization and the assimilation of a new social status. The following section presents the identity negotiation mechanisms that lead to the implementation of one strategy over another. There appears to be three key identity mechanisms: search for consistency with former identities, comparison with other consumers (present identity), and projection into future identities. In addition, the evolution of physical and cognitive abilities and of family support tends to play a role in the balance between disengagement and engagement. This is why we call these "facilitating factors".

\section{Search for consistency with former identities}

Moving into a nursing home is often experienced as a bereavement. Statements by some staff members confirmed this: "It's important to remember that [...] moving into a nursing home is a first bereavement, mourning one's past life, one's autonomy, and ... going into a nursing home is even a dispossession. They are dispossessed of their property, choices, financial resources. So it's a whole parameter, an overall vision that's necessary" (Staff member no. 21). Going into a nursing home is a break with the normal life course, and individuals need to deal with the loss of the personal and social capital they have built up over the course of their life. Thus, the first mechanism identified consists of a comparison between current and former self - what one no longer is, what one can no longer do, and what one can still do. Identity negotiation consists of integrating this new experience into one's life story. The three coping areas identified can be used to illustrate this:

Former habits and routines. Residents adopt an engagement-type strategy more easily if life in the nursing home mirrors the habits and roles from the person's former life. Jeanne, for 
example, had a very busy professional life and had never liked cooking. The nursing home has provided her with some degree of comfort: no need to cook and the possibility of being able to chat (Family member no. 16). She thus copes relatively easily with her new life by using engagement strategies (routinization: relying on the service as a reference point; socialization: creating and developing social relationships; assimilation of a new social role: finding the positives in the situation). The same is true for Marcel and Richard whose wives used to do the shopping and cooking (Family members no.12 and no.13). However, coping was more complicated for Denise, Marthe and Simone: Denise enjoyed going out and eating in good restaurants (Family member no. 20), Marthe worked in the restaurant business and loved to cook (Family member no. 17), and Simone cooked as a means of recognition (Family member no. 19). In these cases, life in the nursing home created a rupture with former identities and in the beginning generated great frustration and the adoption of disengagement-type strategies.

Former sociability. Since mealtimes are shared in a community, a person's level of sociability and, more generally, their personality traits are important factors for explaining the type of strategy adopted. A shy or introverted person will tend to mobilize disengagement-type strategies, particularly with regard to socialization and assimilation of the new social status, while someone who is more sociable and/or extroverted will tend to mobilize engagement-type strategies. Huguette (Resident no.9), for example, who defines herself as a person with good social skills, very quickly made friends with other residents (socialization: creating and developing social relationships). She has taken a strong interest in how the nursing home functions, has asked to visit the central kitchen and is proactive in suggesting ways to improve things (routinization: improving the organization). She has also adopted an active approach towards regaining autonomy as soon as possible (for example, she regularly requests permission to leave the residence to buy fruit in the local shop).

Former life events and social status. Former life events and the acceptance - or not - of the role of dependent person helps to explain the type of coping strategy mobilized. For some, transition to the role of "dependent person" is gradual and had already begun at home (e.g. meal deliveries, home help). However, it is more of a shock when this dependent role is the result of an accident (e.g. stroke, bad fall). Beyond these temporal elements (anticipated vs sudden), adaptation is facilitated if people have made the decision themselves to use the service. This is the case for Colette (Resident no. 5) who did not want to go back to live with her domineering husband after she was hospitalized, or André (Resident no. 4) who moved into the residence in anticipation of mobility problems and to support his wife who was already a resident. For them, the process of adjustment is a relatively good one and happens proactively.

In short, individuals are more likely to adopt engagement-type strategies if the conditions of using the service resonate with elements from their past, whereas disengagement-type strategies are more often adopted when the current situation is too different from that of their former life. This identity work is dynamic, and once new habits have been integrated into the sense of self, it then becomes difficult to change them: "Some things become rituals, and it's troublesome for some people to change them. For instance, there's one lady who, every evening eats soup, two or three slices of ham, her portion of pasta, her yoghurt, her sugar, her bread and butter. It's a real ritual for her. What can you do about it? We're not going to upset her by making her have something different" (Staff member no. 31). This identity negotiation dynamic explains how individuals move from disengagement (e.g. denying reality) to composition (e.g. creating a personal routine) and then to engagement (e.g. taking on certain tasks within one's capabilities) as they manage to integrate the elements of the service into their sense of self. 


\section{Social comparison}

Since people live in a community and generally eat together, social comparison is omnipresent. This comparison mechanism can lead individuals to adopt disengagement or engagement strategies depending on whether they consider their situation to be more or less favourable than that of their peers. Dignity then becomes a central question: "Some people are messy eaters and how other people look at them hurts them inside" (Staff member no. 30). Thus, the pressure of how other people see them is often uncomfortable for those in the poorest health, who therefore tend to adopt social avoidance and disengagement strategies (e.g. socialization: wanting to be alone; assimilation of new social status: isolating themselves). Dining with people who have such eating difficulties can also negatively impact others due to the mirror effect: "It's true that some residents have difficulty eating. [...] It can put others off their meal because they are a bit disgusted, it turns their stomach to see someone drooling a bit, or if someone has food falling out of their mouth. I've heard residents say that that it made them lose their appetite." (Staff member no. 33). Georges, a resident, confirmed this: "It's hard and it gets you down! [...] You see people who are bedridden already ... When they get up, when they come into the dining room, they need help to eat. When you see this, you start feeling depressed, you know." (Resident no. 8). Like Georges, these negative affects related to seeing peers in uncomfortable positions can make others want to adopt a disengagement posture (e.g. needing to be alone), but also an active posture such as the creation of solidarity or the determination to regain autonomy to avoid reaching this state of dependency.

\section{Projection into the future}

As seen previously, residents are very focused on the present and talk little about the future. Indeed, moving into a nursing home is an event that is generally seen as the last chapter in one's life: "It's a stage that usually ends with death ..." (Staff member no. 29). In other words, the illness and physical or cognitive decline that conditions the service consumption makes it difficult for individuals to project into the future and leads them towards disengagement: "I no longer feel able. [...] My Parkinson's is progressing [...] Oh yes, so it's difficult. Things are not looking good. I can still walk, I don't know, I don't think that's going to last much longer" (Resident no. 10). Some consider food to be a lever that preserves their health and autonomy for as long as possible. Controlling one's food intake provides a sense of control: "I make sure that I eat well and in sufficient quantities but without excess. I was told years ago that when you eat too much, you dig your own grave with your teeth" (Resident no. 4). Thus, as residents project themselves into the future, they are looking to stay alive and, above all, healthy for as long as possible, which means taking an active role such as forcing themselves to eat even if they do not have much appetite: "Frankly, we don't know how our situation will evolve [...]. There are days when it's difficult for me, but I still try to eat. Otherwise, if you don't eat, you get sick. I'd rather eat than take the drugs" (Resident no. 9). Some go even further and actively take charge of their health without referring to medical advice: "I eat too much here. I cut down on breakfast after I weighed myself, oh dear. I went from 80 to $90 \mathrm{~kg}$ in no time. I thought, 'Oh dear'. I corrected my diet and dropped back down to 84. 84, 85, I'll have to cut down a little later. [Did you decide to cut down or did the doctor tell you to do it?] No, no, no-one. It was my decision. You know, an empty bag doesn't stand upright, right? Well neither does one that's too full!" (Resident no. 7). Nevertheless, future projections are difficult because death is omnipresent, it is inescapable due to the commemorative plaques and flowers that are regularly placed in the common areas in memory of residents who have passed away. These gestures are well-intentioned and appear to be essential for respecting the memory of those who have passed, however, the unintended consequence of this is that it is a reminder of death and inhibits projections for the future. 


\section{Facilitating factors}

Strictly speaking, facilitating factors are not identity negotiation mechanisms (such as those we have just described: search for consistency with former identities, social comparison, projection into the future). Physical and cognitive skills, as well as support from relatives, play an important moderating role in the adoption of one strategy or another. In other words, the links between identity negotiation mechanisms and disengagement/engagement-type coping strategies can be different depending on the physical and cognitive skills and family support available.

Physical and cognitive skills. Physical and cognitive skills are important factors for explaining the coping strategies implemented. However, many people do not express their thoughts spontaneously in a nursing home, and it was striking to note that the staff interviewed during the participant observations did not always know the reasons behind this silence. The question thus arises as to the nature of the disengagement of non-communicating people - is it suffered or voluntary? As one respondent noted: "Sometimes it's difficult to guess what noncommunicating people are thinking ... sometimes you can guess by their facial expressions, but not always. I think that when you put something good and tasty in your mouth, it shows on your face. But residents who are bedridden or who cannot eat without assistance often have the impression of being force-fed" (Staff member no. 21). Disengagement is clearly not voluntary when it is linked to Alzheimer's disease or other cognitive degeneration pathologies that cause a loss of spatial and temporal points of reference. For these residents, relying on the collective routine is simply a way of getting their bearings: "At noon or 11:30am, the room starts to fill up. The residents start moving towards the dining room. There are more people hovering in the hall outside the dining room at 11:30 than at any other time. It's the same in the evening. Indeed, it gives their day a sense of rhythm and routine" (Staff member no. 21).

Family support. As with the previous factor, support from relatives can facilitate the adoption of engagement-type strategies, and the absence of such support can lead individuals to adopt disengagement-type strategies. The support of relatives is itself conditioned by several factors. First of all, the nature of the family ties. Depending on the relationship between the relative and the resident (spouse, child, sibling), frequency of visits and involvement in nursing home living conditions, and food in particular, can all vary. The spouses we met came almost every day; their visit usually took place during the evening meal for residents who needed help eating. Family history is also important. In particular, past relationships with the resident can influence the frequency of visits and the support given in the nursing home. For example, Josette's daughter (Family member no. 15) had many fond memories of family meals, cooking and moments shared in the kitchen. Her mother loved to cook and passed on a love of good meals with fresh, natural produce. This explains why her daughter was very attentive to what went into Josette's meals. When the family is present, they push their mother to adopt active approaches. Regarding routinization, they bring little treats (sweets, fruit, etc.) that boost and maintain the creation of personal rituals around collective routines. And for assimilation of the new social status, families act as the residents' ally in their quest for autonomy, particularly with regard to a change in diet. For example, Jeanne's daughter (Family member no. 16) lobbied the doctor because her mother was forbidden to eat sweets: "Yes, because you can't deprive a 94-year-old lady of a bar of chocolate just because she has to watch what she eats... no. At a certain age, we have to stop all that. But I talked to the doctor about it. She told me that if, for example, we give chocolates or sweets to someone who's not really allowed to eat them, afterwards, she told me, the treatment would have to be adjusted. But you shouldn't deprive them either, because those are the only small pleasures they have left." 


\section{DISCUSSION}

\section{Summary of contributions and main results}

This research explores strategies for coping with vital service captivity when the service plays a major role in a person's daily life. The literature has examined the process of coping with vital captive services by focusing on the service experience, or on how the consumer arranges their life to find some form of normality - through the sharing of roles and tasks or through seeking social support. This study goes further and considers cases of when "no exit is possible", where the service becomes a non-negotiable part of a person's life and the individual has to integrate it into their sense of self. This is important because the construction of a coherent life history gives meaning and is an integral part of eudaimonic well-being, especially for vulnerable people like the elderly. The first contribution of this research is that it showed that coping with vital service captivity - from engagement to disengagement - is a differential process. The results indicate that residents implement several coping strategies simultaneously, and that these strategies can overlap: adaptation to the institution's routine, socialization with other actors, and assimilation of a social role as a dependent person. This echoes coping strategies already identified in the literature for other types of archetypal captivity such as the strategies used to make one's voice heard again (e.g. being aggressive), regaining a form of choice or power by attempting to act on the environment (e.g. participating in or improving the organization) (e.g. Rayburn, 2015; Filless and Volker, 2020). The contribution here is to show that coping strategies are not uniform; a person may try to become involved in the institution's routine (e.g. taking on certain tasks within their capabilities) while at the same time disengaging from social relationships (e.g. wanting to be alone). The second contribution is to show that these coping strategies were not created in a vacuum but, on the contrary, have several underlying identity negotiation mechanisms. The balance between disengagement and engagement is achieved through a process of identity negotiation which takes into account former life trajectory, future prospects and social comparisons, but also changes in physical or cognitive skills and family support.

A more in-depth understanding and awareness of these coping strategies and identity negotiation mechanisms allows us to highlight some unintended consequences to resident wellbeing that are caused by the service captivity situation:

First, the standardized organization due to health constraints and limited human and financial resources is often criticized because it does not give much freedom to the residents. However, this scheduled organization can play a crucial role in the well-being of the residents: faced with a seemingly insurmountable gap between their former lives and reduced future prospects, some residents focus on the present and value this routine as a form of stability. Reliance on the service as a reference point appears to be a necessary preliminary step to creating personal rituals and participating in the organization of the service. However, the drawback is that this process of progressive habituation means that less attention is given towards improving the environment (e.g. using tablecloths and putting flowers in the room has little immediate effect on the appreciation of the service as a whole).

Second, living in a community is another specificity of nursing home life that creates a captivity in the service. The coping strategies implemented by residents can have both positive consequences (e.g. creating and developing social relationships, creating solidarity) and negative ones (e.g. feeling ashamed, being aggressive). It is difficult to predict the outcome as it depends on a process of social comparison with people in various states of health and 
capabilities, as well as on the actions, mood and well-being of all stakeholders (other residents, staff).

This holistic vision of coping with a vital service, as seen through an identity negotiation lens, allows us to identify several areas of discussion within the TSR movement, to promote well-being within vital services, and to limit the negative unintended consequences of collective senior care.

Taking into account the differential coping process and their consequences on resident wellbeing

The results show that coping with food in nursing home is a differential process which is far from uniform and which takes different forms in different psychological and social contexts routinization, socialization, and assimilation of the social role. An individual may thus simultaneously adopt different strategies in these different areas. This is the case when a resident is disengaged from routine while at the same time being highly engaged in the social life of the nursing home. Therefore, this study calls for a closer look at the different strategies that individuals develop, and the diversity of the resulting balances. More generally, it calls on us to qualify the conceptions underlying the theories of successful ageing. Indeed, what the two opposing figures of ageing derived from disengagement theory (Cumming and Henry, 1961) and activity theory (Havighurst, 1963) have in common is that they approach ageing insofar as it is successful, i.e., that the strategy adopted is accepted by the individual, that it suits them and brings them satisfaction (Caradec, 2004). Our results are in line with a more nuanced vision corresponding to the concept of "detachment" (Caradec, 2004; Clément et al., 2018) since the actors may "no longer have control" over certain things or relationships, and do not rule out the possibility that they may still have control over others. Given the new constraints such as those linked to going into a nursing home, people will disengage from certain activities and social relationships so that they can preserve others that may be essential and significant to them. In other words, quality of life can only be understood if all facets are considered. This conception leads us to broadly question the very notion of "satisfaction" in the use of such services (Bangerter et al., 2017). In this logic, the idea is not so much to seek consumers' satisfaction but rather to facilitate their inner harmony by accompanying them in the detachment from certain activities or relationships and supporting them in those that remain.

\section{A co-adaptation process between member of staff and resident}

Continuity with a former life is a very significant factor underlying the coping strategies implemented by residents. Our results show that this continuity is unavoidably broken in the nursing home and residents must adapt to the staff, in terms of both the social and the logistical aspects inherent in the service. Observations and time spent in the nursing homes show that this adaptation work is reciprocal. The staff, for the most part, are well aware of residents' habits and preferences and try to be attentive to their particular needs. However, they are not necessarily aware of life histories and former habits. This is unfortunate as awareness of residents' former habits, personality and social identities affords a better understanding of their reactions in the present. And a better understanding of their past makes it possible to find solutions, and to mobilize other, more personal and individual levers to convince a person to eat, and more generally, to help them to adapt. Thus, better knowledge of residents' life history is crucial. This can be achieved through arrival interviews guided by autobiographical methods (e.g. Birren and Deutchman, 1991; Sherman, 1991), reminiscence (e.g. Guillemot and Urien, 2010) or a life story interview (e.g. McAdams et al., 1997), and more systematic inclusion 
and/or solicitation of relatives. These "life stories", a kind of library of one's previous life, should be made available to staff so that they can refer to them to find elements of understanding and action levers. Members of staff could gradually enrich these stories as new conversations take place and the resident develops new habits. Of course, given the nature of community life, not all personal habits can be taken into consideration. This is why the institution must also describe its organizational constraints more clearly to residents - better knowledge leads to greater compliance. These suggestions would make it possible to engage in a genuine cocreation logic (Feng, Altinay and Olya, 2019) which would facilitate the articulation of personal rituals around collective constraints.

\section{Empowering elderly residents to make projections into the future}

Besides the continuity with former identities, our study also shows the importance of identity projection into the future. Indeed, projecting oneself into the future, continuing to develop, creating new projects and forming goals to be achieved are essential components of subjective well-being (Diener, Sapyta and Suh, 1998), and this is especially true for elderly people (Plaud and Guillemot, 2015). The results of the study also show that the people who project themselves the most into the future are the most likely to take ownership of the service and develop engagement-type strategies such as decorating their room, developing new sociability, or doing their utmost to maintain maximum autonomy. However, as the results of this study also show, identity projection into the future is difficult to do in a nursing home. Beyond the context and objective health elements that led the residents to go into a nursing home in the first place and the age-related decline in energy, death is omnipresent and many tangible elements are reminders of this (e.g. commemorative plaques and flowers regularly placed in common areas in memory of the residents who have passed away). In such a context in which death is so salient, the relationship to time and the time remaining to live theories are relevant here (e.g. Carstensen, Isaacowitz and Charles, 1999). They show that when individuals are aware that the time they have left to live is limited, they tend to invest themselves either in behaviours aimed at maximizing pleasure to enjoy this time, or in behaviours aimed at preserving their health to extend it (Gourmelen et al., 2016). However, the actual functioning of the nursing homes studied (hyper-medicalization) tends to focus on the need for care and to suppress the search for pleasure. So how can we help residents to project themselves into the future? The results identify several levers. The first involves reactivating pleasure by giving less room to healthrelated aspects reflecting illness- and death-related images. One way of doing this is by making the catering area less sanitized and more of a "living space" than a "healthcare space". The second is to give residents deadlines to help them project themselves into the future. The positive impact of this shone through in the smiles and tone of voice of the residents who told us about special moments organized during activities, such as the "inter-home" baking competition in which residents made cakes and tasted other peoples'. However, these are ad hoc events announced with short notice; putting in place a calendar of similar events, such as parties, entertainment, themed meals, etc. could help to punctuate the life of the individuals consuming the service and enable them to project themselves into the medium-term future. A third lever consists of providing support for residents in the activation of psychosocial processes aimed at accepting finiteness and symbolically prolonging their existence beyond their own death, such as generativity or spirituality (e.g. Erikson, 1959; Butler, 1963). This can be achieved by enabling them to see the treasures they possess (memories, etc. - positive ageism Gergen and Gergen, 2002), by helping them to pass on their knowledge (equipping nursing homes with videoconferencing facilities to communicate with geographically remote family, creating links with the younger generation through school visits, etc.), or by helping them to 
resolve conflicts, inject more meaningfulness, and build a coherent and complete life story. For, as McAdams (2001) points out, a good story is judged by how it ends.

\section{Being attentive to the process of "forced" social comparison}

Findings highlight that social comparison with those considered to be better or worse off than oneself has a major impact on the coping strategies adopted. Comparing oneself to a person in a worse situation than one's own is a well-known and well-documented coping strategy that is used to accept one's own situation (e.g. Baltes and Baltes, 1990; Henchoz, Cavalli and Girardin, 2008). The present study shows that when this social comparison mechanism is "forced" - for example, by making people eat together -, this can have harmful effects as it sends the individual an image of themselves that they are not ready or willing to confront. Members of staff justify collective meals by citing organizational (easiness) and social (efforts not to isolate the most dependent people) imperatives. However, as the results show, when people with disparate states of dependency have to live together, this can have unintended effects (e.g. depression, withdrawal) and may not systematically reinforce the hoped-for solidarity or support. This finding therefore opens up a complex debate on the diversity and inclusion of the most dependent people. There is no magic solution, but one possibility would be to offer residents more choice. Partitioning off eating areas and creating spaces where people can eat alone or in groups, and at different times freely chosen within a defined time frame would have the advantage of leaving more room for personal habits, facilitating sociability by grouping individuals who have the same expectations, and avoiding negative social comparisons.

\section{Limitations and avenues for future investigation}

This study used a holistic approach to understand the coping strategies that people adopt with vital service captivity. However, the study has several limitations, particularly with regard to the contributions and how they were informed, for example, staff and families were asked to give their opinion on the coping strategies adopted by the residents and this could lead to interpretation bias. To limit these biases, we worked upstream with the residence managers to identify families and staff with good knowledge of the residents: i.e., families who are present every day or almost every day, and staff involved and interested in such food issues in the nursing home. In addition, the feedback sessions in the nursing homes ensured that the views and interpretations converged with those of the residents. Nevertheless, the study would probably have benefitted from a more in-depth analysis of the experiences of staff, who are key actors in the processes inherent in coping with service captivity. Indeed, individual adaptation to a negative service also implies adapting the service (through the staff) to the needs of the elderly residents. We interviewed members of staff because we wanted to learn more about consumers' coping strategies and to explore the staff's perception of the process. It would also be relevant to examine how staff members adapt to the consumers. Do staff also experience a learning curve or adaptation? What are their motives and responsibilities, and what skills are they based on? What is the place of affect in these processes? All of these questions warrant further examination as they cohere with the recommendations made in this study and, again, underline the need for a holistic approach. While the feedback sessions in the nursing homes led us to draw up these recommendations, it is clear that such policies need to be weighed against the concrete realities of managing a facility of this type. Our findings call for more research that combines other management areas such as human resources to ensure that issues of well-being, for consumers and staff alike, are at the heart of the matter when managing negative services. 
Another limitation is the narrow focus of the research topic, i.e., food in a nursing home. Here we studied a situation of 'extreme' captivity that involved a complete break with the residents' former life, one that involved changing their place of residence. It would be interesting to extend the study to other situations (private nursing homes, assisted living, mealson-wheels, etc.) to broaden the analysis and offer other viewpoints. Moreover, in a more general perspective, we need to extend our knowledge of vital services. Unfortunately, this type of service, which is crucial for the subsistence of vital needs, must develop under environmental (e.g. migration), social (e.g. poverty) and demographic (e.g. ageing population) challenges. Further research is needed on how individuals use such services, and, if they have no choice but to use them, how they adapt. Thus, it is possible to vary the contexts (social services, medical services), and culture (the present study was conducted in France) or to link adaptation to other constructs such as satisfaction (or dissatisfaction), quality of life and well-being.

Furthermore, this research also calls for consideration of the cohort effect in such studies. Indeed, the dependent elderly consumer of tomorrow will not be the same as today's dependent elderly consumer. Individuals build their identity based on cultural markers, i.e., education and collective events experienced during their youth. However, in terms of consumption, the generation who are currently in nursing homes (those born in the 1930s and early 1940s) are not demanding: they were raised in a period of wartime restrictions, avoid being "difficult" and very rarely complain. This will no doubt change with the arrival of the baby boom generation: boomers have grown up and evolved with the consumer and service society, they are much more heterogeneous in terms of eating habits (both in variety and pace of meals), are used to having a choice, and are far more demanding. Finally, in a more conjunctural context, the health measures taken to counter Covid-19, with very strict social distancing rules (e.g. limited family visits, eating meals alone in one's room) have had a significant impact on the frailest nursing home residents. However, this study underscores the importance of family support and sociability with other residents. The impact of the health crisis on the well-being of the elderly should be studied through a routinization lens (restrictive and changing health protocol) socialization (very limited, sometimes even absent due to physical distancing) and social status (even more vulnerable because this regards an at-risk population).

\section{Funding}

The author(s) disclosed receipt of the following financial support for the research, authorship, and/or publication of this article: This study is funded by Region BRETAGNE as part of the NUTRICHIC research program.

\section{Acknowledgement}

The authors thank the region of Brittany for the funding of this research project, as well as the Cornouaille Hospital for its collaboration. The authors especially thank the caregivers, residents and families for their time. The authors thank their colleague Sylvie Codo and the association "Aux goûts du jour" who participated in the data collection.

\section{REFERENCES}

Anderson, Laurel, Amy L., Ostrom, Canan Corus, Raymond P. Fisk, Andrew S. Gallan, Mario Giraldo, Martin Mende, Mark Mulder, Steven W. Rayburn, Mark S. Rosenbaum, Kunio Shirahada, and Jerome D. Williams (2013), "Transformative Service Research: An Agenda for The Future," Journal of Business Research, 66 (8), 1203-1210. 
Baltes, Paul B., and Margaret M. Baltes (1990). "Psychosocial perspective on successful aging: the model of selective optimization with compensation," in Successful aging: Perspectives from the behavioral science, Baltes P.B and Baltes M.M (Eds),. New York: Cambridge University Press, 1-34.

Bangerter Lauren R., Allison R. Heid, Katherine Abbott, and Kimberley Van Haitsma (2017), "Honoring the Everyday Preferences of Nursing Home Residents: Perceived Choice and Satisfaction With Care," The Gerontologist, 57(3), 479-486.

Barnhart, Michelle and Lisa Peñaloza (2013), "Who Are You Calling Old? Negotiating Old Age Identity in The Elderly Consumption Ensemble," Journal of Consumer Research, 39 (6), 1133-1153.

Beatson, Amanda, Aimee Riedel, Marinella Chamorro-Koc, Greg Marston, and Lisa Stafford (2020). "Increasing the independence of vulnerable consumers through social support," Journal of Services Marketing, 34(2), 223-237. doi /10.1108/JSM-09-2019-0327.

Birren, James E., and Donna E. Deutchman (1991), Guiding Autobiography Groups for Older Adults: Exploring the Fabric of Life, Baltimore: Johns Hopkins University Press

Bomhoff, Manja and Roland Friele (2017). "Complaints in long-term care facilities for older persons: Why residents do not give "free advice"”. Health Policy, 121(1), 75-81. doi /10.1016/j.healthpol.2016.11.007.

Bowblis, John R. and Andrew Ghattas (2017), "The Impact of Minimum Quality Standard Regulations on Nursing Home Staffing, Quality and Exit Decisions," Review of Industrial Organization, 50, 43-68.

Bundgaard, Karen M. (2005), "The meaning of everyday meals in living units for older people", Journal of Occupational Science, 12 (2), 91-101.

Butler, Robert N. (1963), "The Life Review: An Interpretation of Reminiscence in The Age," Psychiatry, 26, 65-75.

Caradec, Vincent (2004), Vieillir après la retraite, Approche sociologique du vieillissement. Paris : Presses Univ. de France.

Carstensen, Laura L., Derek M. Isaacowitz, and Susan T. Charles (1999). "Taking time seriously: A theory of socioemotional selectivity." American Psychologist, 54(3), 165-181. https://doi.org/10.1037/0003-066X.54.3.165.

Choi, Namkee G., Sandy Ransom, and Richard J. Wyllie (2008), "Depression in older nursing home residents: The influence of nursing home environmental stressors, coping, and acceptance of group and individual therapy," Aging \& mental health, 12, 536-547.

Clément, Serge, Marcel Drulhe, Jean Mantovani and Monique Membrado (2018), " Genèse de la déprise, » Gérontologie \& Société, 40(155), 27-32.

Cumming, Elaine and William E. Henry (1961), Growing Old: The Process of Disengagement. New York: Basic Books.

Davis, Kathryn S., Mayoor Mohan, and Steven W. Rayburn (2017), "Service quality and acculturation: advancing immigrant healthcare utilization", Journal of Services Marketing , 31 (4/5), 362-372. https://doi.org/10.1108/JSM-03-2016-0118.

Desai, Vinit M. (2012), “The Two Faces of Voluntary Disclosure: Quality Improvement and Organisational Learning From Self-Reported Problems," British Journal of Management, 23, 344-360. 
Diener, Ed, Jeffrey J. Sapyta and Eunkook Suh (1998), "Subjective Well-Being is Essential to Well-Being". Psychological Inquiry, 9 (1), 33-37.

Donnelly, Sarah., Marita O’Brien, Emer Begley, E. and John Brennan (2016), "I'd prefer to stay at home but I don't have a choice" Meeting Older People's Preference for Care: Policy, but what about practice?" Dublin: University College Dublin. https://www.ageaction.ie.

Drolet Aimee, Norbret Schwarz and Carolyn Yoon (2011), The Aging Consumer: Perspectives from Psychology and Economics, NY: Routledge.

Echeverri, Per and Nicklas Salomonson (2019) "Consumer vulnerability during mobility service interactions: causes, forms and coping", Journal of Marketing Management, 35(3/4), 364-389. Doi.10.1080/0267257X.2019.1568281.

Erikson, Erick H. (1959), Identity and the life cycle: selected papers, New York: International Universities Press.

Feng, Kuo., Levent Altinay and Hossein Olya (2019), "Social well-being and transformative service research: evidence from China", Journal of Services Marketing, Doi: 10.1108/JSM10-2018-0294.

Fliess, Sabine and Maarten Volkers (2020), "Trapped in a Service Encounter: Exploring Customer Lock-In and Its Effect on Well-Being and Coping Responses During Service Encounters," Journal of Service Management, 31 (1), 79-114.

Gergen, Kenneth J. and Mary M. Gergen. (2000). "The New Aging: Self-Construction And Social Values". in The Evolution of the Aging Self: The Societal Impact on the Aging Process, Schaie F.W. and Hendricks J. (Eds). New York: Springer, 281-306.

Gergen Mary M. and Kenneth J. Gergen. (2002). "Positive Aging: New Images For A New Age". Ageing International, 27(1), 3-23. DOI: 10.1007/s12126-001-1013-6.

Gherardi, Silvia and Giulia Rodeschini (2015), "Caring as a Collective Knowledgeable Doing: About Concern and Being Concerned," Management Learning, 47 (3), 266-284.

Gioia, Dennis A., Kevin G. Corley, and Aimee L. Hamilton (2013). "Seeking Qualitative Rigor in Inductive Research: Notes on the Gioia Methodology," Organizational Research Methods 16(1), 15-31. https://doi.org/10.1177/1094428112452151.

Gourmelen, Andréa, Bertrand Urien, and Marine Le Gall-Ely (2016). "Ultimate time pressure: Conceptualisation and measurement". Recherche et Applications En Marketing (English Edition), 31(4), 5-27. https://doi.org/10.1177/2051570716658466.

Grenade, Linda, and Duncan Boldy (2008), "Social isolation and loneliness among older people: issues and future challenges in community and residential settings," Australian Health Review, 32(3), 468-78.

Grougiou, Vassiliki, and Simone Pettigrew (2011). "Senior Customers' Service Encounter Preferences.", Journal of Service Research, 14(4), 475-88, https://doi.org/10.1177/1094670511423785.

Guérin Laura (2016), «Faire Manger» et «Jouer le Jeu de la Convivialité» en Etablissement d'Hébergement pour Personnes Agées Dépendantes (EHPAD). De l'Intensification des Contraintes de Travail Pendant le Service des Repas, SociologieS, http://journals.openedition.org/sociologies/5404.

Guillemot, Samuel, and Bertrand Urien (2010), "Legacy writing among the elderly: conceptual bases, dimensioning and a proposed scale for measuring motivations", Recherche et 
Applications En Marketing (English Edition), 25(4), 25-43. https://doi.org/10.1177/205157071002500402

Guillemot, Samuel, and Bertrand Urien (2016), "Legacy Writing and the Consumption of Biographic Services", Psychology \& Marketing, 33(11), 971-981. https://doi.org/10.1002/mar.20931

Gurrieri, Lauren, and Jenna Drenten (2019), "Visual storytelling and vulnerable health care consumers: normalising practices and social support through Instagram", Journal of Services Marketing, 33(6), 702-720. doi /10.1108/JSM-09-2018-0262.

Haber, David (2006), "Life Review: Implantation, Theory, Research and Therapy," International Journal of Aging and Human Development, 63(2), 153-171.

Hare, Caroline, James Law, and Carole Brennan (2013), "The vulnerable healthcare consumer: An interpretive synthesis of the patient experience literature", International Journal of Consumer Studies, 37(3), 299-311. doi-org.scd-proxy.univ-brest.fr/10.1111/ijcs.12006.

Havighurst, Robert J. (1963), "Successful ageing", in Process of ageing, R. Williams, C. Tibbitts and W. Donahue (eds.), Vol. 1., New York: Atherton.

Henchoz, Karine, Stefano Cavalli, and Myriam Girardin (2008). «Perception de la santé et comparaison sociale dans le grand âge», Sciences sociales et Santé, 26(3) : 47-72. DOI : $10.3917 /$ sss.263.0047.

Huff, Aimee D. and June Cotte (2016), "The Evolving Family Assemblage: How Senior Families "Do" Family," European Journal of Marketing, 50 (5/6), 892-915.

Hutton, Martina (2016). "Neither passive nor powerless: Reframing economic vulnerability via resilient pathways", Journal of Marketing Management, 32(3-4), 252-274. doi.org/10.1080/0267257X.2015.1118144.

Karanika, Katerina and Margaret K. Hogg (2016), "Consumption through the Ambivalent Prism of Intergenerational Support”, European Journal of Marketing, 50 (3/4), 575-601

Kristiansen, Margrethe, Aud Obstfelder and Ann Therese Lotherington (2015), "Nurses' Sensemaking of Contradicting Logics: An Underexplored Aspect of Organisational Work in Nursing Home" Scandinavian Journal of Management, 31, 330-337.

Lambert-Pandraud, Raphaëlle and Gilles Laurent (2010). "Why Do Older Consumers Buy Older Brands? The Role of Attachment and Declining Innovativeness," Journal of Marketing 74(5), 104-121.

Lazarus, Richard S. and Susan Folkman (1984), Stress, Appraisal and Coping, New York: Springer Publishing Company.

Marquier, Rémy, Thomas Vroylandt, Marie Chenal, Pierre Jolidon, Thibaut Laurent, and Camille Peyrot (2016), "Des Conditions de Travail en EHPAD Vécues comme Difficiles par des Personnels très Engagés," Les Dossiers de la DREES, 5, 1-32.

Mason, Marlys and Teresa Pavia (2006). "When the Family System Includes Disability: Adaptation in the Marketplace, Roles and Identity," Journal of Marketing Management, 22(910), 1009-1030, DOI: 10.1362/026725706778935637.

McAdams, Dan. P. (2001), "Unity and purpose in Human lives: The emergence of identity as a life story," in Studying persons and lives, Rabin, A.I.; Zucker, R.A.; Emmons, R.A. and Franck, S. (Eds), NY: Spinger, 148-200. 
McAdams, Dan P., Ann Diamond, Ed de StAubin and Elizabeth Mansfield (1997), "Stories of commitment: The psychosocial construction of generative lives," Journal of Personality and Social Psychology, 72 (3), 678-694.

Miller, Elisabeth G., Barbara E Kahn, and Luce Mary F. (2008), "Consumer wait management strategies for negative service events: A coping Approach," Journal of Consumer Research, 34, 635-648.

Miller, Elizabeth G., Mary F. Luce, Barbara E. Kahn, and Emily F. Conant (2009), "Understanding Emotional Reactions for Negative Services: The Impact of Efficacy Beliefs and Stage in Process," Journal of Services Research, 12 (1), 87-99.

Mittelstaedt, John D., Charles R. Duke, and Robert A. Mittelstaedt (2009), "Health Care Choices in the United States and the Constrained Consumer: A Marketing Systems Perspective on Access and Assortment in Health Care", Journal of Public Policy \& Marketing, 28 (1), 95-101. doi:10.1509/jppm.28.1.95.

Morgan, Ivor and Jay Rao (2006), "Growing Negative Service," MIT Sloan Management Review, 47 (3), 69-74.

Moschis George P., Jill Mosteller and Choong Kwai Fatt (2011), "Research Frontiers on Older Consumers' Vulnerability,” The Journal of Consumer Affairs, 45 (3), 467-491.

Moschis George P. (2019), Consumer Behavior over the Life Course Research Frontiers and New Directions, New York: Springer.

Otalora, Mauricio L., Mark S. Rosenbaum, and Augusto R. Orejula (2018) "Understanding health care service quality in developing Latin America," Health Marketing Quarterly, 35(3), 167-185. doi:10.1080/07359683.2018.1514733.

Ostrom, Amy L., A. Parasuraman, A., David E. Bowen, Lia Patrício, and Christopher A. Voss (2015). "Service research priorities in a rapidly changing context," Journal of Service Research, 18, 127-159. doi:10.1177/1094670515576315.

Phipps, Marcus and Julie L. Ozanne (2017). "Routines Disrupted: Reestablishing Security through Practice Alignment", Journal of Consumer Research, 44(2), 361-380.

Plaud, Cécile and Samuel Guillemot (2015), "Service Interactions and Subjective Well-Being in Later Life," Journal of Services Marketing, 29 (4), 245-254.

Rayburn, Steven W. (2015), “Consumers' captive service experiences: it's YOU and ME," The Service Industries Journal, 35 (15-16), 806-825.

Rayburn, Steven W., Marlys J. Mason, and Maarten Volkers. (2020), "Service Captivity: No Choice, No Voice, No Power,” Journal of Public Policy \& Marketing, 39(2), 155-168.

Riedl, Maria, Franco Mantovan, and Christa Them (2013), "Being a Nursing Home Resident: A Challenge to One's Identity," Nursing Research and Practice, 1-9. https://doi.org/10.1155/2013/932381.

Rosenbaum, Mark. S. (2015). “Transformative service research: Focus on well-being”. Service Industries Journal, 35(7-8), 363-367. doi:10.1080/02642069.2015.1025061.

Schau, Hope Jensen, Mary C. Gilly, and Mary Wolfinbarger (2009), "Consumer Identity Renaissance: The Resurgence of Identity-Inspired Consumption in Retirement," Journal of Consumer Research, 36 (2), 255-76.

Sebastiano, Antonio, Valeria Belvedere, Alberto Grando, and Antonio Giangreco (2017), "The Effect of Capacity Management Strategies on Employees' Well-Being: A Quantitative 
Investigation into The Long-Term Healthcare Industry," European Management Journal, 35 (4), 563-573.

Sharma, Shikha, Jodie Conduit, and Sally Rao Hill (2017), "Hedonic And Eudaimonic WellBeing Outcomes From Co-Creation Roles: A Study Of Vulnerable Customers," Journal of Services Marketing, 31(4/5), 397-411.

Sherman, Edmund (1991), Reminiscence and the Self in old age, New-York: Springer.

Singh, Sangeeta and Lola C. Duque (2012), "Moderating Role of Stress in Evaluating Negative Services: Encounters with the Police," Journal of Services Research, 15 (2), 231-241.

Spanjol, Jelena, Anna S. Cui, Cheryl Nakata, Lisa K. Sharp, Stephanie Y. Crawford, Yazhen Xiao, and Mary Beth Watson-Manheim (2015), "Co-production of Prolonged, Complex, and Negative Services: An Examination of Medication Adherence in Chronically Ill Individuals," Journal of Service Research, 18(3), 284-302.

Sury, Laura, Kim Burns, and Henry Brodaty (2013), "Moving in: adjustment of people living with dementia going into a nursing home and their families," International Psychogeriatrics, $25,867-876$.

Timko, Christine and Rudolf H. Moos (1989), "Choice, Control and Adaptation among elderly residents of Sheltered Care setting”, Journal of Applied Psychology, 19 (8), 636-655.

Trees, Rachel and Dianne Marion Dean (2018), "Physical and emotional nourishment: Food as the embodied component of loving care of elderly family relatives," European Journal of Marketing, 52 (12), 2405-2422.

Twigg, John (2004), Disaster risk reduction: mitigation and preparedness in development and emergency programming. Overseas Development Institute.

Vercauteren, Richard and Bernard Hervy (2002), L'animation dans les établissements pour personnes âgées, Manuel des pratiques professionnelles, Pratiques gérontologiques, Toulouse : Eres Editions.

Verleye, Katrien, Paul Gremmel, and Deva Rangarajan (2014), "Managing Engagement Behaviors in a Network of Customers and Stakeholders: Evidence from the Nursing Home Sector," Journal of Service Research, 17 (1), 68-84.

Welté, Jean-Baptiste (2019), "Identity Negotiation of Older People in a Mobility Context: The Case of Train Journeys," Recherche et Applications En Marketing (English Edition). https://doi.org/10.1177/2051570719845302.

Westin, Lars, and Ella Danielson (2007), "Encounters in Swedish nursing homes: a hermeneutic study of residents' experiences," Journal of Advanced nursing, 60 (2), 172-180. 